\title{
DENDROFLORA ZABYTKOWEGO PARKU DWORSKIEGO W EDWARDOWIE (POZNAŃ, WIELKOPOLSKA)
}

\author{
WOODY PLANTS IN THE HISTORICAL MANOR PARK IN EDWARDOWO \\ (POZNAŃ, GREATER POLAND REGION)
}

\author{
Joanna Bykowska, Agnieszka Ptak \\ J. Bykowska, A. Ptak, Katedra Dendrologii, Sadownictwa i Szkółkarstwa, Uniwersytet Przyrodniczy \\ w Poznaniu, Dąbrowskiego 159, 60-594 Poznań, Poland, e-mail: joanna.bykowska@mail.up.poznan.pl
}

(Received: February 19, 2018. Accepted: March 26, 2018)

\begin{abstract}
Aвstract. The article presents the current state of woody plants in the historical park at the Edwardowo manor and grange complex in Poznań. 921 trees, one individual shrub, 11 groups of shrubs and 3 specimens of vines were inventoried in the park area, i.e. 1.5 ha. The tree stand in the park mostly consists of angiosperm trees. According to geographical and historical classification, native species of apophytes are the most numerous group.
\end{abstract}

KEY wORDs: zabytkowy park dworski, dendroflora, folwark Edwardowo

\section{WSTĘP}

Poznań, będący stolicą Wielkopolski, przez wieki był ważnym ośrodkiem politycznym, gospodarczym i społecznym. Na przestrzeni minionych stuleci jego powierzchnia się zmieniała. Po zabudowaniu terenu otoczonego murami obronnymi nastąpił rozwój osadnictwa poza nimi i w najbliższych okolicach miasta, po obu brzegach Warty (JACKOWIAK 1993 za Gąsiorowskim 1973 i Zajchowską 1977). Od lokacji na lewym brzegu rzeki w 1253 roku aż do połowy XX wieku Poznań rozrastał się głównie w kierunku zachodnim. Dopiero w drugiej połowie XX wieku odnotowano zjawisko nasilonej ekspansji infrastruktury miejskiej na obszary położone na terenie wschodniej (prawobrzeżnej) części wysoczyzny morenowej oraz na północ od centrum miasta (BARTKOWSKI 1981).

Z punktu widzenia współczesnego Poznania istotne były zmiany, które nastąpiły po likwidacji części fortyfikacji. Po roku 1900, w kolejnych latach i dziesięcioleciach w granice administracyjne rozrastającego się miasta włączono przylegające do niego podmiejskie wsie i osady. Ich nazwy są obecnie nazwami wielu dzielnic i osiedli Poznania. Na obszarze przyłączanych miejscowości istniały i funkcjonowały majątki ziemskie - zespoły pałacowo- lub dworsko-parkowe - oraz folwarki. Według GoszczYŃsKIEJ (2004) do czasów współczesnych przetrwało zaledwie ok. 30 $z$ nich. Obiekty te są $w$ różnym stanie. Od dobrze utrzymanych po zupełnie zapomniane i zaniedbane. Jednym $z$ ładniejszych istniejących obiektów jest secesyjna willa na Edwardowie wraz z najciekawszą na terenie całego Poznania kolonią domów pracowników folwarcznych.

Folwark Edwardowo powstał prawdopodobnie w drugiej połowie XIX wieku (GoszcZYŃsKa 2004). Obecnie jest on położony w zachodniej części Poznania, w pobliżu portu lotniczego Ławica. Dwór otoczony parkiem oraz zabudowania folwarku znajdują się po północnej stronie ulicy Bukowskiej (nr 237), natomiast kolonia domów pracowników folwarcznych po stronie południowej (ul. Bukowska 248, $250,252,254)$.

Zespół folwarczny, w którego skład wchodzą willa, park, ogrodzenie $z$ bramami obok willi oraz cztery czworaki i cztery budynki gospodarcze z ogrodzeniem, został wpisany do rejestru zabytków 5.12.1992 
r. i 10.03.2011 r. pod nr rej.: 833/Wlkp/A (WyKAZ ZABYTKÓW... 2017).

Park w stylu krajobrazowym został założony w końcu XIX wieku i powiększony w wieku XX. Obecnie zajmuje obszar ok. 1,5 ha. W jego wschodniej części znajduje się secesyjny dwór (willa), wybudowany na początku XX wieku. Jest to parterowy budynek z mieszkalnym poddaszem, murowany z cegły, nakryty dwuspadowym dachem (pokrytym dachówka) z naczółkami. Dwór wzniesiono na planie prostokąta $z$ ryzalitami od strony północnej, wschodniej i południowej, z dwutraktowym układem pomieszczeń na parterze (GoszczYŃsKa 2004).

Do sierpnia 2015 roku dwór i park były własnością Agencji Mienia Wojskowego. Obecnie stanowią własność prywatną.

Celem przeprowadzonych badań była szczegółowa inwentaryzacja dendroflory parku.

\section{METODY BADAN}

Prace inwentaryzacyjne wykonano latem 2014 roku i wiosną 2015 roku. Ze względu na bardzo liczne samosiewy szczegółowym pomiarom i obserwacjom poddano drzewa o obwodzie pnia powyżej $20 \mathrm{~cm}$ oraz wszystkie krzewy i pnącza. Zmierzono obwód pnia każdego $\mathrm{z}$ uwzględnionych drzew na wysokości $130 \mathrm{~cm}$ od powierzchni gleby (wyniki podano $\mathrm{w} \mathrm{cm}$ ). U okazów wielopniowych oraz o pniu rozwidlonym poniżej $130 \mathrm{~cm}$ każdy przewodnik (pień) zmierzono oddzielnie. Wysokość drzew ustalono za pomocą fińskiego wysokościomierza SUUNTO PM-5/1520. Ustalano także wysokość i przybliżoną powierzchnię zarastania krzewów i pnączy (wyniki podano $\mathrm{w} \mathrm{m}^{2}$ ). Nazewnictwo taksonów przyjęto według SENETy \& Dolatowskiego (2011). Przynależność gatunków do odpowiednich grup geograficzno-historycznych

Tabela 1. Wykaz roślin drzewiastych rosnących na terenie parku dworskiego w Edwardowie Table 1. A list of woody plants in Edwardowo manor park

\begin{tabular}{|c|c|c|c|c|}
\hline $\begin{array}{l}\text { Rodzina } \\
\text { Family }\end{array}$ & $\begin{array}{l}\text { Takson } \\
\text { Taxon }\end{array}$ & $\begin{array}{c}\text { Liczba okazów } \\
\text { Number of specimens }\end{array}$ & GGH & $\mathrm{FZ}$ \\
\hline \multicolumn{5}{|c|}{$\begin{array}{l}\text { Gromada nagozalążkowe } \\
\text { Division Gymnosperms }\end{array}$} \\
\hline Pinaceae & Picea abies (L.) H. Karst. & 106 & Ken & $\mathrm{M}$ \\
\hline \multicolumn{5}{|c|}{$\begin{array}{l}\text { Gromada okrytozalążkowe } \\
\text { Division Angiosperms }\end{array}$} \\
\hline \multirow[t]{2}{*}{ Salicaceae } & Populus nigra L. 'Italica' & 3 & $\mathrm{D}$ & M \\
\hline & Populus $\times$ canadensis Moench & 3 & $\mathrm{D}$ & M \\
\hline Juglandaceae & Juglans regia $\mathrm{L}$. & 2 & Ken & M \\
\hline Betulaceae & Betula pendula Roth & 26 & Ap & M \\
\hline Ulmaceae & Ulmus laevis Pall. & 14 & Ap & M \\
\hline Moraceae & Morus alba L. & 129 & $\mathrm{D}$ & M \\
\hline Viscaceae & Viscum album L. subsp. album & - & Ap & $\mathrm{Ch}$ \\
\hline Hydrangeaceae & Philadelphus coronarius L. & 1 & $\mathrm{D}$ & $\mathrm{N}$ \\
\hline \multirow[t]{2}{*}{ Rosaceae } & Prunus cerasifera Ehrh. & 6 & Ken & M \\
\hline & Prunus cerasifera Ehrh. & $\begin{array}{l}3 \text { grupy } \\
3 \text { groups }\end{array}$ & Ken & $\mathrm{N}$ \\
\hline Leguminosae & Robinia pseudoacacia L. & 10 & Ken & M \\
\hline \multirow[t]{3}{*}{ Aceraceae } & Acer platanoides L. & 589 & Ap & M \\
\hline & Acer pseudoplatanus $\mathrm{L}$. & 7 & Ap & M \\
\hline & Acer negundo L. & 7 & Ken & M \\
\hline Hippocastanaceae & Aesculus hippocastanum $\mathrm{L}$. & 16 & $\mathrm{D}$ & M \\
\hline \multirow[t]{2}{*}{ Tiliaceae } & Tilia platyphyllos Scop. & 1 & Ap & M \\
\hline & Tilia cordata Mill. & 1 & Ap & M \\
\hline Araliaceae & Hedera helix L. & 3 & Ap & $\mathrm{Ch}$ \\
\hline Oleaceae & Fraxinus excelsior $\mathrm{L}$. & 1 & Ap & M \\
\hline \multirow[t]{2}{*}{ Caprifoliaceae } & Sambucus nigra L. & $\begin{array}{l}1 \text { grupa } \\
1 \text { group }\end{array}$ & Ap & $\mathrm{N}$ \\
\hline & Symphoricarpos albus var. laevigatus (Fernald) S.F. Blake & $\begin{array}{l}8 \text { grup } \\
8 \text { groups }\end{array}$ & $\mathrm{D}$ & $\mathrm{N}$ \\
\hline
\end{tabular}

Objaśnienia:

GGH (grupa geograficzno-historyczna): Ap - apofit, D - diafit, Ken - kenofit.

FŻ (forma życiowa): $\mathrm{Ch}$ - chamefit, $\mathrm{M}$ - megafanerofit, $\mathrm{N}$ - nanofanerofit.

Explanations:

GGH (geographic-historical group): Ap - apophyte, D - diaphyte, Ken - kenophyte.

FŻ (life form): $\mathrm{Ch}$ - chamaephyte, $\mathrm{M}$ - megaphanerophyte, $\mathrm{N}$ - nanophanerophyte. 
określono na podstawie opracowań CHMiela (1993) i JACKOWIAKA (1993), natomiast formy życiowe Raunkiæra opisano, posługując się opracowaniem ZARZYCKIEgo i in. (2002). Przybliżony wiek drzew oszacowano za pomocą tabeli wiekowej (MAJDECKI 1980/86).

\section{WYNIKI}

$\mathrm{Na}$ terenie objętym badaniami zinwentaryzowano 921 drzew, jeden krzew rosnący pojedynczo, 11 grup krzewów oraz trzy okazy pnączy. Korony topoli kanadyjskich (Populus $\times$ canadensis Moench) zasiedlone były przez liczne krzewy jemioły pospolitej (Viscum album L. subsp. album) (tab. 1).

Drzewostan parku w Edwardowie tworzą głównie drzewa okrytozalążkowe, stanowiące prawie $90 \%$ wszystkich rosnących w parku drzew. Poszczególne okazy tej grupy roślin są przedstawicielami 15 taksonów z 11 rodzajów należących do 11 rodzin. Aż osiem rodzajów, a jednocześnie rodzin, jest reprezentowanych wyłącznie przez jeden gatunek (tab. 1).

Pod względem klasyfikacji geograficzno-historycznej najliczniejszą grupą są gatunki rodzime z grupy apofitów, reprezentowane przez 10 gatunków, stanowiących ponad $70 \%$ całej zinwentaryzowanej dendroflory. Pozostałe dwie grupy obejmują głównie gatunki obcego pochodzenia. Do diafitów zaliczono sześć taksonów, a do kenofitów cztery gatunki (tab. 1).

Rośliny drzewiaste odnotowane $\mathrm{w}$ parku są przedstawicielami jedynie trzech form życiowych. Zdecydowanie dominują megafanerofity (15 taksonów). Nanofanerofity są reprezentowane przez cztery, a chamefity przez dwa gatunki (tab. 1).
W składzie gatunkowym wyraźnie dominuje klon pospolity (Acer platanoides L.). Stanowi on ok. $64 \%$ wszystkich drzew rosnących w parku (tab. 1). Brak regularnej pielęgnacji terenu, zwłaszcza po opuszczeniu obiektu przez wojsko (w zabytkowej willi siedzibę miała m.in. Wojskowa Administracja Koszar), sprawił, że ten ekspansywny gatunek stworzył w wielu miejscach bardzo gęste grupy samosiewów. Ponadto $\mathrm{w}$ południowo-zachodniej części parku ok. 10 lat temu posadzono szpaler z 15 klonów pospolitych jako nasadzenie kompensacyjne po usunięciu innych drzew $\mathrm{w}$ związku $\mathrm{z}$ prowadzonymi na terenie obiektu pracami budowlanymi (inf. ustna).

Wyjątkowym, rzadko spotykanym współcześnie składnikiem dendroflory parkowej jest morwa biała (Morus alba L.). Na terenie Edwardowa zinwentaryzowano aż 129 drzew tego gatunku. Część z nich rośnie w północnej części parku, wokół okrągłego betonowego placu. Prawdopodobnie dawniej drzewa te tworzyły altanę lub otaczały budynek altany. Być może tworzyły również aleję prowadzącą do tego miejsca, ale obecnie układ ten jest nieczytelny. $\mathrm{Z}$ powodu dużego zacienienia morwy rosnące $\mathrm{w}$ tej części obiektu są $\mathrm{w}$ złej kondycji. Wiele $z$ nich zamiera, ma silnie pochylony pień oraz liczny posusz $\mathrm{w}$ koronie. $\mathrm{Z}$ kolei morwy rosnące $\mathrm{w}$ alei $\mathrm{w}$ zachodniej części parku są wyjątkowo zdrowe. Prawdopodobnie dawniej były one cięte na wysokości ok. 1,3-1,6 m (tab. 1).

Trzecim gatunkiem pod względem liczebności jest świerk pospolity (Picea abies (L.) H. Karst.). Wzdłuż północnej granicy parku 106 drzew tworzy aleję (tab. 1). Ich oszacowany wiek (tab. 3) wskazuje, że utworzono ją prawdopodobnie w latach 70. XX wieku. Widoczne jeszcze pniaki pozwalają na stwierdzenie, że pierwotnie świerki posadzono $\mathrm{w}$ dwóch rzędach po

Tabela 2. Wymiary drzew zinwentaryzowanych w parku w Edwardowie Table 2. The dimensions of trees inventoried in Edwardowo manor park

\begin{tabular}{|c|c|c|c|c|c|c|c|}
\hline \multirow{2}{*}{$\begin{array}{l}\text { Takson } \\
\text { Taxon }\end{array}$} & \multicolumn{6}{|c|}{$\begin{array}{c}\text { Obwód pnia }(\mathrm{cm}) \\
\text { Trunk circumference }(\mathrm{cm})\end{array}$} & \multirow{2}{*}{$\begin{array}{c}\text { Wysokość }(\mathrm{m}) \\
\text { Height }(\mathrm{m})\end{array}$} \\
\hline & $\begin{array}{l}\text { od-do } \\
\text { from-to }\end{array}$ & $20-50$ & $51-100$ & $101-150$ & $151-200$ & $\begin{array}{l}\text { powyżej } 200 \\
\text { greater than } 200\end{array}$ & \\
\hline Acer negundo L. & $29-181$ & 2 & 2 & 1 & 2 & - & $9-16$ \\
\hline Acer platanoides L. & $30-218$ & 303 & 244 & 24 & 15 & 3 & $5-19$ \\
\hline Acer pseudoplatanus L. & $44-143$ & 1 & - & 6 & - & - & $10-18$ \\
\hline Aesculus hippocastanum L. & $75-200$ & - & - & 12 & 4 & - & $15-16$ \\
\hline Betula pendula Roth & $25-170$ & 14 & - & 4 & 8 & - & $4-24$ \\
\hline Fraxinus excelsior $\mathrm{L}$. & 121 & - & - & 1 & - & - & 15 \\
\hline Juglans regia $\mathrm{L}$. & $90-117$ & - & 1 & 1 & - & - & $10-15$ \\
\hline Morus alba L. & $53-150$ & - & 120 & 9 & - & - & $6-13$ \\
\hline Picea abies (L.) H. Karst. & $50-145$ & 2 & 86 & 18 & - & - & $7-20$ \\
\hline Populus $\times$ canadensis Moench & $231-331$ & - & - & - & - & 3 & $16-22$ \\
\hline Populus nigra L. 'Italica' & $110-191$ & - & - & 2 & 1 & - & $17-22$ \\
\hline Prunus cerasifera Ehrh. & $50-53$ & 3 & 3 & - & - & - & 6 \\
\hline Robinia pseudoacacia L. & $56-188$ & - & 3 & 6 & 1 & - & $7-17$ \\
\hline Tilia cordata Mill. & 200 & - & - & - & 1 & - & 13 \\
\hline Tilia platyphyllos Scop. & 192 & - & - & - & 1 & - & 14 \\
\hline Ulmus laevis Pall. & $56-263$ & - & 2 & 8 & 2 & 2 & $12-20$ \\
\hline
\end{tabular}


obu stronach drogi. Obecnie z powodu silnego ocienienia i zwarcia koron wszystkie zinwentaryzowane okazy mają mocno oczyszczone pnie oraz niewielkie, wysoko osadzone korony.

W południowej części parku zachowała się fragmentarycznie aleja z kasztanowca pospolitego (Aesculus hippocastanum L.). Prowadziła ona niegdyś od dworu w kierunku bramy wjazdowej i dalej w kierunku kolonii domów pracowników folwarcznych. Obecnie w alei rośnie 15 drzew. Na liściach wszystkich okazów stwierdzono objawy żerowania szrotówka kasztanowcowiaczka (Cameraria ohridella Deschka \& Dimić) (tab. 1).

W drzewostanie parku w Edwardowie dominują drzewa, których obwód pnia na wysokości $130 \mathrm{~cm}$ od powierzchni gleby nie przekracza $50 \mathrm{~cm}(325$ okazów) lub wynosi od 51 do $60 \mathrm{~cm}$ (kolejnych 218 okazów). Drzew okazałych jest niewiele. Obwód pnia powyżej $151 \mathrm{~cm}$ osiągnęły zaledwie 43 okazy (tab. 2). Najgrubszymi pniami wyróżniają się trzy topole kanadyjskie $(231,305$ i $331 \mathrm{~cm})$, trzy klony pospolite $(203,210$ i $218 \mathrm{~cm})$ oraz dwa wiązy szypułkowe (204 i $263 \mathrm{~cm}$ ).

Drzewa rosnące w parku w Edwardowie są roślinami młodymi. Wiek 424 okazów, możliwy do oszacowania na podstawie tabeli Majdeckiego, nie przekracza 30 lat. Drzew ponad stuletnich jest zaledwie dziewięć: osiem klonów pospolitych (szacunkowy wiek 101-125 lat) i jeden wiąz (ok. 112 lat) (tab. 3).

Park w Edwardowie cechuje bardzo uboga warstwa krzewów (tab. 1). Na terenie obiektu odnotowano zaledwie cztery gatunki $z$ tej grupy roślin. Trzy $z$ nich tworzą 11 jednogatunkowych grup, zajmujących powierzchnię od ok. 1,8 do prawie 20 $\mathrm{m}^{2}$. W większości rosną one przy drogach. Najliczniej występującym gatunkiem jest niewymagająca w stosunku do stanowiska, ekspansywna śnieguliczka biała (Symphoricarpos albus var. laevigatus (Fernald) S.F. Blake).

Pnącza są reprezentowane tylko przez bluszcz pospolity (Hedera helix L.) (tab. 1). Ze względu na niewielkie rozmiary roślin można przypuszczać, że gatunek ten pojawil się $\mathrm{w}$ parku niedawno. Pojedyncze pędy jednego $z$ okazów wspinają się po pniu klonu pospolitego (nr inw. 211). Dwa pozostałe okazy rosną jako rośliny okrywowe, zajmując powierzchnię ok. 1,5 i $2,5 \mathrm{~m}^{2}$.

\section{DYSKUSJA}

Park w Edwardowie to jedno z kilkunastu założeń, które do czasów współczesnych przetrwały na terenie Poznania w obrębie zabytkowych kompleksów dworsko- i pałacowo-parkowych lub folwarcznych. Nie zachowała się niestety żadna dokumentacja, która przedstawiałaby pierwotną kompozycję i strukturę gatunkową dendroflory tego obiektu. GosZcZYŃsKA (2004 za Goryńską 1993) wspomina jedynie, że w drzewostanie dominują jesiony, kasztanowce, klony, lipy, robinie i świerki, a przez park prowadzi aleja $z$ topoli włoskiej. Z pewnością na stan i wygląd obiektu wpłynął okres około 50-letniego użytkowania przez wojsko, ale również nie ma żadnych dostępnych informacji na ten temat. Istotne znaczenie dla obecnego kształtu całego założenia dworsko-folwarcznego w Edwardowie miała rozbudowa ul. Bukowskiej. W sierpniu 2010 roku przesunięto zabytkową bramę folwarku wraz z fragmentem ceglanego muru o kilkadziesiąt metrów na północ od ich pierwotnego położenia. Jednocześnie zmniejszyła się powierzchnia parku w części południowo-wschodniej.

Tabela 3. Przybliżony wiek wybranych taksonów drzew zinwentaryzowanych w parku w Edwardowie Table 3. The approximate age of selected tree taxa inventoried in Edwardowo park

\begin{tabular}{|c|c|c|c|c|c|c|}
\hline \multirow{2}{*}{$\begin{array}{l}\text { Takson } \\
\text { Taxon }\end{array}$} & \multicolumn{5}{|c|}{$\begin{array}{l}\text { Wiek drzew w latach } \\
\text { Age of trees in years }\end{array}$} & \multirow{2}{*}{$\begin{array}{l}\text { Suma } \\
\text { Total }\end{array}$} \\
\hline & $\begin{array}{c}\text { poniżej } 30 \\
\text { up to } 30\end{array}$ & $31-50$ & $51-75$ & $76-100$ & $\begin{array}{l}\text { powyżej } 100 \\
\text { over } 100\end{array}$ & \\
\hline Acer negundo L. & 4 & 3 & - & - & - & 7 \\
\hline Acer platanoides L. & 394 & 152 & 18 & 17 & 8 & 589 \\
\hline Acer pseudoplatanus L. & 1 & - & 4 & 2 & - & 7 \\
\hline Aesculus hippocastanum L. & - & 12 & 4 & - & - & 16 \\
\hline Betula pendula Roth & 14 & 2 & 9 & 1 & - & 26 \\
\hline Fraxinus excelsior L. & - & - & 1 & - & - & 1 \\
\hline Picea abies (L.) H. Karst. & 6 & 86 & 14 & - & - & 106 \\
\hline Populus $\times$ canadensis Moench & - & 1 & 2 & - & - & 3 \\
\hline Populus nigra L. 'Italica' & 2 & 1 & - & - & - & 3 \\
\hline Robinia pseudoacacia L. & 1 & 2 & 6 & 1 & - & 10 \\
\hline Tilia cordata Mill. & - & - & - & 1 & - & 1 \\
\hline Tilia platyphyllos Scop. & - & - & - & 1 & - & 1 \\
\hline Ulmus laevis Pall. & 2 & 1 & 9 & 1 & 1 & 14 \\
\hline $\begin{array}{l}\text { Suma } \\
\text { Total }\end{array}$ & 424 & 260 & 67 & 24 & 9 & 784 \\
\hline
\end{tabular}


Współczesny skład dendroflory parku w Edwardowie jest zaskakująco inny od stwierdzonego w latach dziewięćdziesiątych XX wieku. W drzewostanie wyraźnie dominuje bowiem klon pospolity, morwa biała, o której GoszCZYŃsKa (2004) w ogóle nie wspomniała, i świerk pospolity. Jesion i dwa gatunki lip są reprezentowane zaledwie przez pojedyncze drzewa, a topola włoska przez trzy okazy rosnące $\mathrm{w}$ alei pomiędzy morwami. Być może w latach 90. usunięto topole włoskie i zastąpiono je morwą białą. Aktualne są natomiast informacje podane przez KIRSCHKE (2007) o szczątkowej alei kasztanowców prowadzącej od willi w kierunku bramy wjazdowej oraz o alei morwowej prowadzącej do willi.

Główną grupą roślin drzewiastych $\mathrm{w}$ parku w Edwardowie są drzewa, co zdaniem Furmanik (2010) jest cechą typową dla XIX-wiecznych ogrodów krajobrazowych. Według PĄGowskiej \& GRABaRKIEWICZ (2002) w założeniach tych najczęściej sadzono gatunki krajowe: buki, dęby, graby, jesiony, klony, lipy, modrzewie, jodły i świerki. Drzewa i krzewy obcego pochodzenia zaczęto chętniej wprowadzać dopiero od przełomu wieku XIX i XX. Spostrzeżenie autorek potwierdzają wyniki badań własnych. Wykazano w nich, że w drzewostanie 1,5-hektarowego parku $\mathrm{w}$ Edwardowie dominują gatunki rodzime. Jest to cecha wielu wielkopolskich parków krajobrazowych, odnotowana w ostatnich latach m.in. przez CZARNĄ i in. (2008, 2009), BYKOWSKĄ (2014), KorSZUN \& BYKOWSKA (2015) oraz NowiŃskĄ i in. (2016).

CZEKALSKi (1988) wspomina, że wiele parków zabytkowych posiada bogate kolekcje drzew i krzewów ozdobnych, często obcego pochodzenia, osiągające znaczne wymiary lub unikatowe w skali kraju. Dendroflorę parku $\mathrm{w}$ Edwardowie cechuje jednak małe zróżnicowanie gatunkowe. Prawie tysiąc zinwentaryzowanych roślin drzewiastych to przedstawiciele zaledwie 21 taksonów. To potwierdza inną tezę CzEKALSKIEGO (1988), że nieduże parki wiejskie, a takim z początku był park w Edwardowie, zazwyczaj cechują się dość ubogim składem gatunkowym. Na terenie obiektu nie rośnie żaden pomnik przyrody ani rzadki, ciekawy gatunek introdukowany. Zgodnie z Rozporządzeniem Ministra Środowiska (RozPorZĄDzenIE... 2017) jedynie dwa wiązy szypułkowe osiągnęły wymiary pomnikowe.

Pomimo różnych przemian, często niekorzystnych, oraz braku regularnej pielęgnacji park w Edwardowie jest wartościowym obiektem przyrodniczym, a wraz ze wszystkim zabytkowymi zabudowaniami - także architektonicznym i historycznym. Według WalerzAKA $i$ in. (2015) nadal możliwa jest restytucja i częściowe przywrócenie pierwotnego układu przestrzennego w obrębie parku oraz odtworzenie niektórych powiązań widokowych i kompozycyjnych z folwarkiem. Autorzy sformułowali swoją tezę na podstawie wyników przeprowadzonych badań terenowych i studialnych, oceny stopnia zniszczenia zabytkowej tkanki obiektu, identyfikacji współczesnych zagrożeń związanych $z$ postępującym procesem urbanizacji oraz analizy stworzonych modeli trójwymiarowych.

\section{PODZIĘKOWANIA}

Autorki dziękują Agencji Mienia Wojskowego w Gorzowie Wielkopolskim za wyrażenie zgody na przeprowadzenie prac inwentaryzacyjnych na terenie parku w Edwardowie. Badania zostały sfinansowane ze środków Katedry Dendrologii, Sadownictwa i Szkółkarstwa Uniwersytetu Przyrodniczego w Poznaniu.

\section{LITERATURA}

BARTKOWSKI T. (1981): Transurbacje miast Wielkopolski i niektóre zagadnienia przestrzenno-planistyczne ich rozwoju oraz zastosowanie do nich niektórych metod fizjografii urbanistycznej. Seria Geografia 22. Wydawnictwo Naukowe UAM, Poznań.

Вүкошsка J. (2014): Zmiany w strukturze dendroflory i kompozycji zabytkowego parku w Sobocie (województwo wielkopolskie). Nauka Przyroda Technologie 8, 1, \#11.

ChMiel J. (1993): Flora roślin naczyniowych wschodniej części Pojezierza Gnieźnieńskiego i jej antropogeniczne przeobrażenia $\mathrm{w}$ wieku XIX i XX. Część 2. Atlas rozmieszczenia roślin. Wydawnictwo Sorus, Poznań.

Czarna A., Klimko M., Janyszek S. (2009): Vascular flora and vegetation of the former manor park in Radojewo (Wielkopolska region, Poland). Roczniki Akademii Rolniczej w Poznaniu 388, Botanika-Steciana 13: 37-47.

CZARna A., Klimko M., WawrzyŃsKa M. (2008). Vascular flora of the palace park in Miłosław (Wielkopolska). Roczniki Akademii Rolniczej w Poznaniu 387, Botanika-Steciana 12: 61-70.

Czekalski M. (1988): Parki wiejskie i ich znaczenie dla kultury. Przegląd Wielkopolski 1: 44-47.

FURMANIK B. (2010): Dobory materiałowe w ogrodach zabytkowych. Kurier Konserwatorski 7: 23-31.

GoszczyŃsKa J. (2004): Majątki wielkopolskie. T. 8. Miasto Poznań. Seria Dawne budownictwo folwarczne. Wydawnictwo Muzeum Narodowego Rolnictwa i Przemysłu Rolno-Spożywczego W Szreniawie, Szreniawa.

JACKOWIAK B. (1993): Atlas rozmieszczenia roślin naczyniowych w Poznaniu. Prace Zakładu Taksonomii Roślin UAM 2. Bogucki Wydawnictwo Naukowe, Poznań.

KiRSCHKE T. (2007): Ewidencja parku dworskiego Edwardowo w Poznaniu. Manuskrypt. Archiwum Miejskiego Konserwatora Zabytków, Poznań.

Korszun S., Byкowska J. (2015): Dendroflora of the castle park in Szamotuły (Wielkopolska Region, Poland). Steciana 19(1): 3-7. 
MAjDECKi L. (1980/86): Tabela wiekowa drzew. Manuskrypt. Oddział Architektury Krajobrazu SGGW, Warszawa.

Nowińska R., Czarna A., Czekalski M., Morozowska M. (2016): Vascular flora of selected palace parks in the Wielkopolska region. Steciana 20(3): 137157.

PąGowska E., Grabarkiewicz A. (2002): Rola parków wiejskich w kształtowaniu bioróżnorodności krajobrazu. Ochrona Roślin 3: 27-28.

RozPORZĄDZENIE Ministra Środowiska z dnia 4 grudnia 2017 roku w sprawie kryteriów uznawania tworów przyrody żywej i nieożywionej za pomniki przyrody. Dz.U. 2017, poz. 2300.

Seneta W., Dolatowski J. (2011): Dendrologia. Wydawnictwo Naukowe PWN, Warszawa.

Walerzak M.T., Świerk D., KrZYŻaniak M., URbańsKi P. (2015). The development of buildings as a threat to the integrity of the Edwardowo estate in the city of Poznan. Czasopismo Techniczne Architektura 5-A: 317-328.

WYKAZ ZABYTKÓw nieruchomych wpisanych do rejestru zabytków stan na 31 grudnia 2017 r. (2017). https://www.nid.pl/pl/Informacje_ogolne/Zabytki_w_Polsce/rejestr-zabytkow/zestawienia-zabytkow-nieruchomych/ (dostęp: 19.01.2018).

Zarzycki K., TrzcińsKa-Tacik H., Różański W., Szeląg Z., Wołek J., Korzeniak U. (2002): Ecological indicator values of vascular plants of Poland. Vol. 2 . Biodiversity of Poland. Ekologiczne liczby wskaźnikowe roślin naczyniowych Polski. T. 2. Różnorodność biologiczna Polski. W. Szafer Institute of Botany, Polish Academy of Sciences, Kraków.

For citation: BYкоWSKA J., PTAK A. (2018): Dendroflora zabytkowego parku dworskiego w Edwardowie (Poznań, Wielkopolska). Steciana 22(1): 29-34. doi:10.12657/steciana.022.004. 